\title{
Persistent secondary hyperparathyroidism caused by parathyromatosis and supernumerary parathyroid glands in a patient on haemodialysis
}

\author{
Jun Yang, Jun Zhang, Ning-hu Liu, Hao Liu and Meng-jie Dong*
}

\begin{abstract}
Background: Secondary hyperparathyroidism (SHPT) is a common high-risk factor for mortality in end-stage renal disease, and parathyromatosis and supernumerary parathyroid glands are very rare causes of persistent SHPT. Preoperative diagnosis and removal of all hyperplastic parathyroid glands are challenging. We report a rare case of persistent SHPT due to parathyromatosis and supernumerary parathyroid glands and successful management by multiple imaging modalities.

Case presentation: A 53-year-old Chinese woman on haemodialysis experienced discomfort due to itching and bone pain due to persistent SHPT after parathyroidectomy. The supernumerary parathyroid glands and parathyromatosis were detected by multiple imaging modalities, including ${ }^{99 \mathrm{~m}} \mathrm{Tc}$-sestamibi $\left.{ }^{99 \mathrm{~m}} \mathrm{Tc}-\mathrm{MIBI}\right) \mathrm{scans}$, ultrasonography and four-dimensional computed tomography (4D-CT) and then excised; pathological confirmation was performed. During follow-up, her serum calcium and parathyroid hormone levels were stable in the appropriate ranges, and no complications arose.

Conclusions: Because of persistent SHPH after parathyroidectomy in patients with haemodialysis, multiple imaging

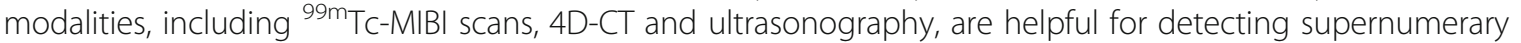
parathyroid glands and parathyromatoses. Accurate preoperative localization of this rare lesion is important for management, enabling the removal of all affected parathyroid tissues.
\end{abstract}

Keywords: Persistent secondary hyperparathyroidism, Parathyromatosis, Supernumerary parathyroid glands, Haemodialysis

\section{Background}

Secondary hyperparathyroidism (SHPT), a common and serious complication of end-stage renal disease (ESRD), is characterized by increased parathyroid hormone (PTH), calcium and phosphate levels, with substantial mortality $[1,2]$. Surgical parathyroidectomy is crucial for patients who are resistant to medical treatment [2].

\footnotetext{
* Correspondence: dmjlzf2016@zju.edu.cn

The Department of Nuclear Medicine, the First Affiliated Hospital, College of Medicine, Zhejiang University, 310003 Hangzhou, People's Republic of China
}

Furthermore, resection of all hyperplastic parathyroid glands is important, as remnant parathyroid glands can be continuously stimulated, leading to persistent or recurrent SHPT, which occurs in $0.4-25 \%$ of cases $[3,4]$. Persistent or recurrent SHPT is attributed to various causes, including failure to identify or entirely remove hyperplastic parathyroid, ectopic, supernumerary parathyroid glands and, very rarely, parathyromatosis [5-8]. Parathyromatosis is very rare and is defined as multiple nests of hyperfunctioning parathyroid tissue [9].

(c) The Author(s). 2020 Open Access This article is licensed under a Creative Commons Attribution 4.0 International License, which permits use, sharing, adaptation, distribution and reproduction in any medium or format, as long as you give appropriate credit to the original author(s) and the source, provide a link to the Creative Commons licence, and indicate if changes were made. The images or other third party material in this article are included in the article's Creative Commons licence, unless indicated otherwise in a credit line to the material. If material is not included in the article's Creative Commons licence and your intended use is not permitted by statutory regulation or exceeds the permitted use, you will need to obtain permission directly from the copyright holder. To view a copy of this licence, visit http://creativecommons.org/licenses/by/4.0/. The Creative Commons Public Domain Dedication waiver (http://creativecommons.org/publicdomain/zero/1.0/) applies to the data made available in this article, unless otherwise stated in a credit line to the data. 


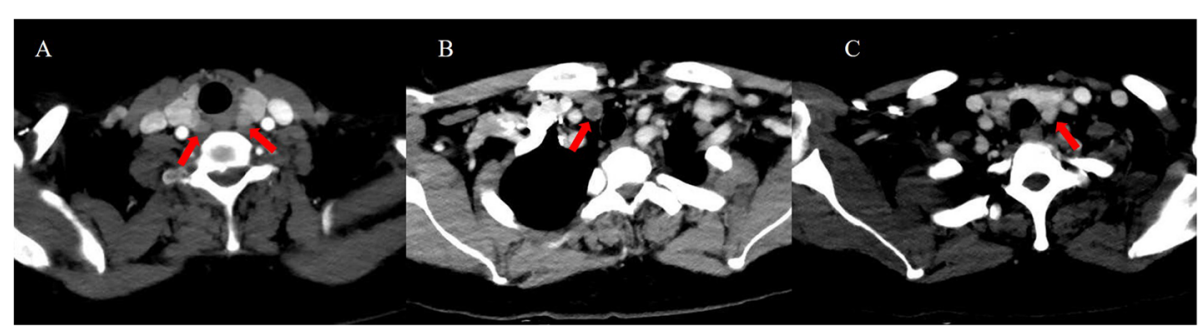

Fig. 1 Axial arterial-phase computer tomography images (A-C) demonstrate four enhanced orthotopic parathyroid glands (the arrows) located posterior or inferior to the thyroid gland
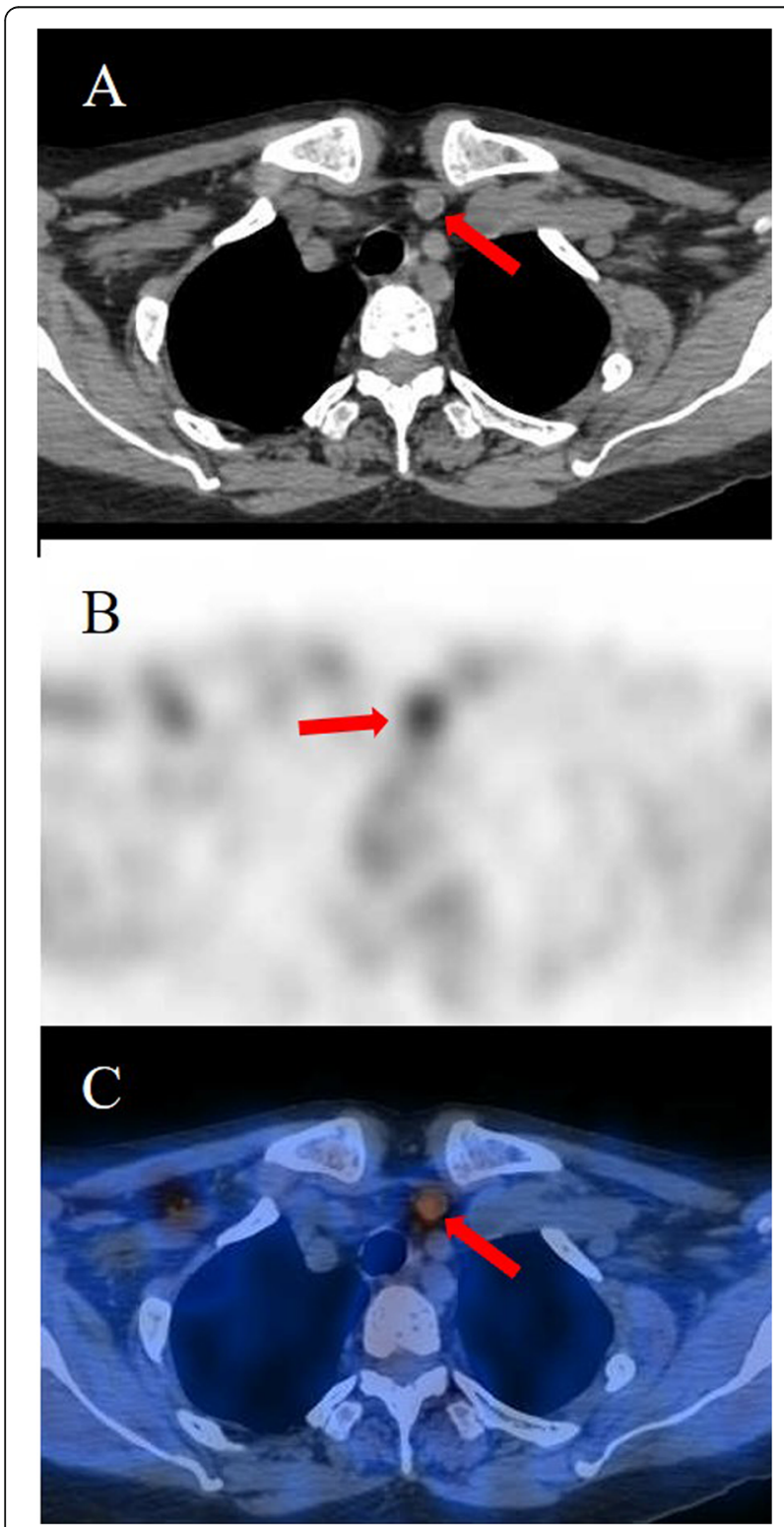

Fig. 2 The ${ }^{99 m} \mathrm{TC}-\mathrm{MIBI}$ SPECT/CT image indicates a low-density lesion with high tracer uptake at the site of the inferior clavicle head (red arrows: A, axial image; $B, S P E C T$; $C$, fusion image)
Preoperative diagnosis and subsequent treatment are challenging. We report a case of persistent SHPT after parathyroidectomy due to parathyromatosis and supernumerary parathyroid glands in a patient with haemodialysis. SHPT was discovered by multiple imaging modalities and successfully managed.

\section{Case presentation}

A 53-year-old Chinese woman had ESDR secondary to obstructive kidney disease and was treated with haemodialysis three times a week regularly since October 2008. She received a living donor kidney graft in May 2008 that was lost 5 months later because of rejection. SHPT was diagnosed based on elevated PTH and hypercalcaemia in July 2014. Although she had taken a vitamin D analogue (calcitriol and caltrate) and phosphate binder (lanthanum carbonate), her PTH and serum calcium levels gradually increased. Since October 2015, the patient had constantly experienced generalized itching. The results of the laboratory tests were as follows (normal ranges in parentheses): serum PTH, 942 pg/mL (1065); serum calcium, $2.64 \mathrm{mmol} / \mathrm{L} \mathrm{(2.03-2.54);} \mathrm{serum}$ phosphate, $3.17 \mathrm{mmol} / \mathrm{L}$ (0.87-1.45); serum alkaline phosphatase, $77 \mathrm{U} / \mathrm{L}$ (40-150). Four-dimensional computed tomography (4D-CT, which originates from the number of phases of imaging, typically 3 , and the change over time, the fourth dimension) of the parathyroid demonstrated four enhanced nodules consistent with orthotopic parathyroid glands (Fig. 1). No remarkable signs of ectopic or supernumerary parathyroid glands were observed. In November 2015, parathyroidectomy was performed to remove the four parathyroid glands, and the right inferior parathyroid gland was transplanted into the nondominant right forearm. On the first postoperative day, tests revealed PTH of $212 \mathrm{pg} / \mathrm{mL}$, serum calcium of $2.43 \mathrm{mmol} / \mathrm{L}$, and serum phosphate of 1.44 $\mathrm{mmol} / \mathrm{L}$, with alleviation of itching. Pathological findings showed parathyroid nodular hyperplasia without evidence of malignancy. Eighteen months after the surgery, she presented with recurred itching and bone pain. Serum calcium and PTH levels were $2.56 \mathrm{mmol} / \mathrm{L}$ and $1631 \mathrm{pg} / \mathrm{mL}$, respectively. Planar ${ }^{99} \mathrm{~m}$ Tc-sestamibi 

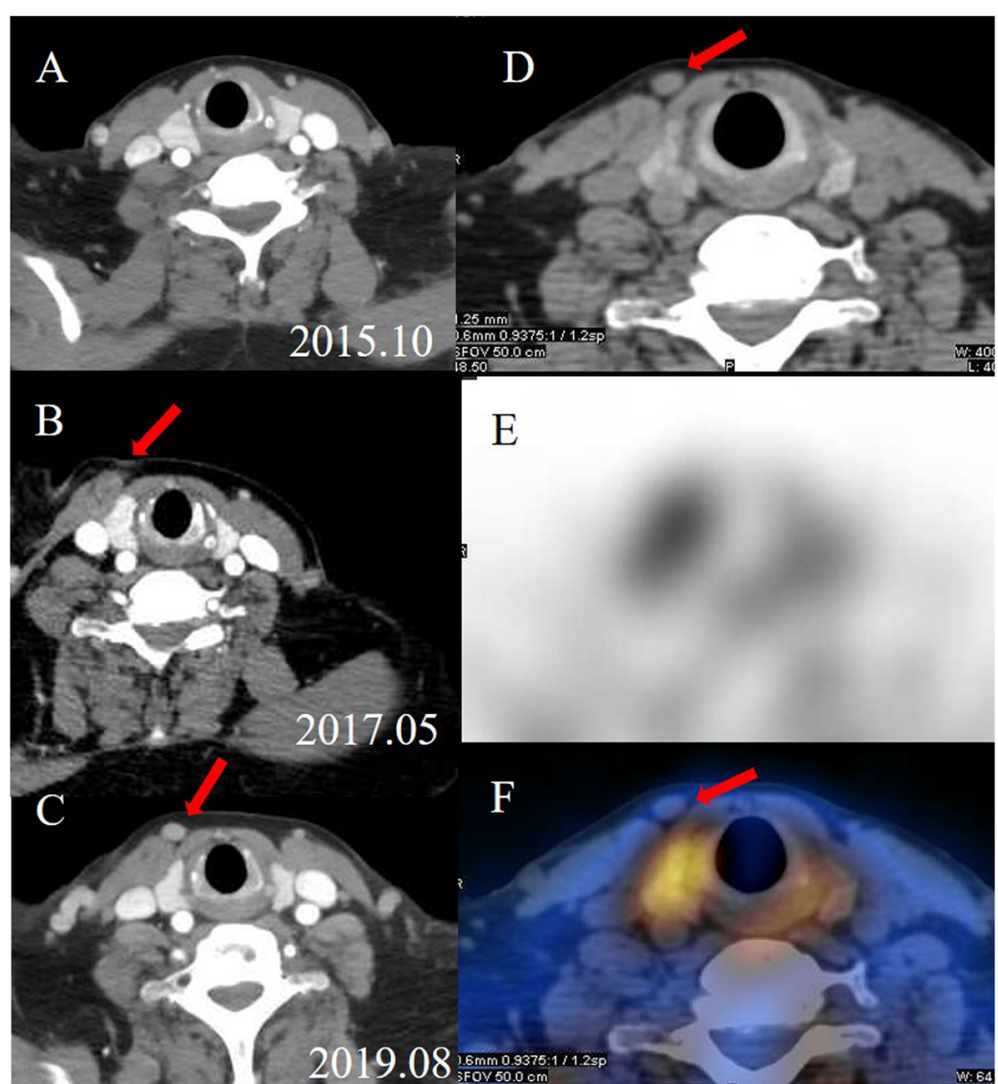

Fig. 3 Serial arterial-phase axial 4D-CT of the parathyroid shows the growth of the right nodule (red arrows) located subcutaneously in the anterior sternocleidomastoid muscle (A, pre-operative; B, 18 months after surgery; C, 46 months after surgery). The ${ }^{99 \mathrm{~m}} \mathrm{TC}-\mathrm{MIBI}$ SPECT/CT image reveals the lesion without tracer uptake (red arrows: $D$, axial image; E, SPECT; F, fusion image)

$\left({ }^{99 \mathrm{~m}} \mathrm{Tc}-\mathrm{MIBI}\right)$ scanning failed to localize the lesion. However, ultrasonography identified a remnant parathyroid gland in the left inferior thyroid, and she subsequently underwent percutaneous ethanol injection therapy (PEIT). On the third day of PEIT, her PTH and serum calcium levels decreased to $447 \mathrm{pg} / \mathrm{mL}$ and 2.15 $\mathrm{mmol} / \mathrm{L}$, respectively. In August 2019, the patient again experienced itching and bone pain and was admitted due to elevated serum calcium of $3.08 \mathrm{mmol} / \mathrm{L}$ and an elevated PTH level of $1593 \mathrm{pg} / \mathrm{mL}$. Physical examination revealed a well-healed cervical surgical scar without a palpable mass. ${ }^{99 \mathrm{~m}} \mathrm{Tc}-\mathrm{MIBI}$ single-photon emission computed tomography/computer tomography (SPECT/CT) indicated focal tracer uptake in the left inferior clavicle

A

\section{B}

$15 \mathrm{~min}$

\section{$120 \mathrm{~min}$}

Fig. $4{ }^{99 \mathrm{~m}} \mathrm{TC}-\mathrm{MIBI}$ planar early (A) and delayed (B) static images demonstrate focal tracer accumulation (red arrows) at the site of autograft 
head (Fig. 2), consistent with the findings of 4D-CT and ultrasonography. A right nodule without tracer uptake was located subcutaneously in the anterior sternocleidomastoid muscle, which was also identified by serial 4DCT (Fig. 3). A ${ }^{99 m}$ Tc-MIBI planar scan also demonstrated focal tracer uptake in the autografted site in the early and delayed phases (Fig. 4), accompanied by a hypoechoic mass on ultrasonography. Three nodules were identified during bilateral neck exploration and then removed (the right subcutaneous nodule, right inferior and left inferior clavicle head were $1.0 \times 0.8 \mathrm{~cm}$, $0.6 \times 0.5 \mathrm{~cm}$ and $1.5 \times 1.0 \mathrm{~cm}$, respectively). On the first day after the operation, the PTH level in a blood specimen obtained from the right arm was 11,226 $\mathrm{pg} / \mathrm{mL}$, whereas it was $1029 \mathrm{pg} / \mathrm{mL}$ from the left arm. In September 2019, surgery to remove the nodules in the autografted site was performed. The next day, her PTH level had decreased to $6.9 \mathrm{pg} / \mathrm{mL}$. Pathological results showed all four nodules to be hyperplastic parathyroid, with several small nodular foci of atypical hyperplastic parathyroid tissue in the fat adjacent to the right inferior remnant parathyroid (Fig. 5). According to the clinical course and pathological findings, parathyromatosis and supernumerary parathyroid glands were confirmed. During 6 months of follow-up, her itching and bone pain improved, and she exhibited appropriate calcium (2.04-2.38 $\mathrm{mmol} / \mathrm{L}$ ) and PTH $(84.4-145.0 \mathrm{pg} / \mathrm{mL})$ levels under regular haemodialysis (Table 1 ).

\section{Discussion and conclusions}

Parathyromatosis and supernumerary parathyroid glands are very rare causes of persistent SHPT after parathyroidectomy in patients undergoing haemodialysis. The form of parathyromatosis is speculated to be either the spillage and seeding of the parathyroid tissue during parathyroid surgery (type 2) or the development of embryonic rests of parathyroid tissue under physiological stimuli (type 1) [9-12]. In our case, one of the causes of the persistent hyperparathyroidism was considered to be type 2 parathyromatosis because both implanted autografts in the forearm and un-implanted subcutaneous seeding were observed. The existing factor of metabolic derangements in ESRD continues to stimulate the growth of implants [13]. Different stages of parathyroid hyperplasia may exist in the same patient because of the heterogeneity of the parathyroid glands with regard to different expression of calcium-sensing receptors, even under the same stimuli. We considered that rupture of the capsule may have occurred during the first parathyroidectomy, as a growth in the right subcutaneous anterior sternocleidomastoid muscle was revealed during serial 4D-CT. According to the literature, most cases are female subjects with ESRD in their fifth to sixth decade of life, which fits the profile of our patient [14]. The other cause of persistent hyperparathyroidism is the supernumerary parathyroid glands, which were overlooked in situ during the first operation; they were located in the left inferior clavicle head. Supernumerary
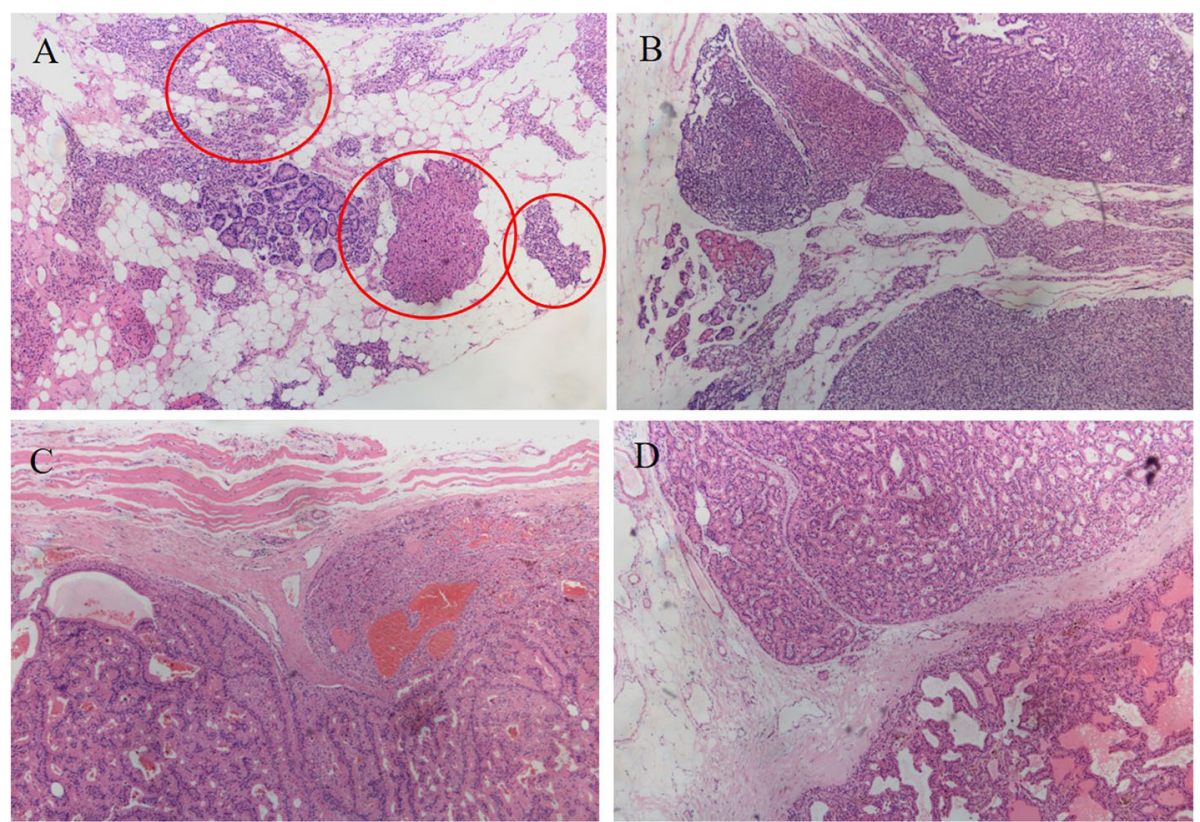

Fig. 5 Histopathology (haematoxylin-eosin staining $\times 50$ ) reveals hyperplastic parathyroid tissues composed of chief cells (A, red circles: microscopic nests of hypercellular parathyroid in the right inferior neck adipose tissue; $B$, supernumerary parathyroid gland; $C$ nodule located in right forearm; D, subcutaneous nodule located anterior sternocleidomastoid muscle) 
Table 1 Changes in laboratory values in response to therapeutic interventions during the last 6 years

\begin{tabular}{lllll}
\hline Time & Treatment & Calcium & Phosphorus & Parathyroid hormone \\
\hline July 2014 & Calcitriol + caltrate +lanthanum carbonate & 2.43 & 1.58 & 171 \\
October 2015 & Before parathyroidectomy & 2.64 & 3.17 & 942 \\
November 2015 & One day after parathyroidectomy + right forearm autograft & 2.43 & 1.44 & 212 \\
May 2017 & Before percutaneous ethanal injection therapy & 2.56 & 2.16 & 1631 \\
& Three days after percutaneous ethanal injection therapy & 2.15 & 1.58 & 447 \\
August 2019 & Before bilateral neck exploration & 3.08 & 2.68 & 1593 \\
September 2019 & Before right forearm autograft resection & 2.58 & 1.68 & 11,226 (right arm) \\
& & & 1029 (left arm) \\
During 6 months of follow-up & regular haemodialysis & 2.17 & 1.25 & 6.9 \\
\hline
\end{tabular}

Calcium (mmol/L, normal 2.03-2.54); Phosphorus (mmol/L, normal 0.87-1.45); Parathyroid hormone (pg/mL, normal 10-65)

parathyroid glands, which are found in approximately $13 \%$ of autopsy and 30-39\% of re-operative cases [5, 15-17], may result from separation of the parathyroid anlage during embryologic migration, and most glands are located in the thymus or superior mediastinum [18]. Knowledge of the anatomy and embryology of parathyroid glands and meticulous handling of parathyroid glands to avoid rupture and spillage during surgery are essential for successful parathyroidectomy. Although complete surgical extirpation of all offending parathyroid nodules is the best option for patients with haemodialysis, it often does not occur [7]. Indeed, the greatest difficulty lies in precise preoperative localization and removal of all disseminated tiny and unexpected nodules of parathyroid tissue [14]. Preoperative imaging can help to identify supernumerary glands and parathyromatosis, but only $40 \%$ of patients are preoperatively diagnosed [7]. Moreover, there is no universally accepted consensus for preoperative localization, as different imaging modalities (ultrasonography, ${ }^{99} \mathrm{~m}$ TcMIBI SPECT/CT, 4D-CT) have various advantages and disadvantages. Depending on the clinical scenario, physicians should choose a suitable image modality. At our institution, US and ${ }^{99 \mathrm{~m}} \mathrm{Tc}-\mathrm{MIBI}$ SPECT/CT are the first-line modalities for re-operation location of parathyroid lesions. When the first-line imaging modalities are negative or discordant, 4D-CT or MRI is used. Fortunately, all of the affected parathyroid nodules were successfully identified and managed in our patient, as also occurred in the rare accounts in the literature [18-20]. Ultrasonography can sometimes identify scattered hypoechoic, hypervascular cervical nodules that appear nonspecific and do not conform to typical anatomic locations of the parathyroid glands [8]. Nonetheless, this modality is operator dependent and unable to assess mediastinal sites, with difficulty in imaging of farposterior lesions [21]. Overall, ${ }^{99 \mathrm{~m}} \mathrm{Tc}$-MIBI SPECT/CT can provide both functional and anatomic information and improve the detection of ectopic/supernumerary glands or farposterior lesions, which ultrasonography is prone to miss. This technique can also reveal uptake foci and has superior
(95\%) positive predictive value [22]. Similar to other studies, some of the lesions in our patients were localized by ${ }^{99 \mathrm{~m}} \mathrm{Tc}$ MIBI SPECT/CT [5, 19, 21, 23]. 4D-CT is a relatively new imaging modality that is characterized by unique perfusion. In a study of 58 patients who had recurrent hyperparathyroidism, the sensitivity of localization of hyperfunctioning parathyroid tissue was $77.4 \%$ for $4 \mathrm{D}-\mathrm{CT}$ compared to $46.0 \%$ for ${ }^{99 \mathrm{~m}} \mathrm{Tc}-\mathrm{MIBI}$ imaging [24]. In our study, serial 4D-CT located the supernumerary parathyroid glands and revealed the growth of parathyromatosis in the subcutaneous anterior sternocleidomastoid muscle in the patient, which was consistent with the literature [18, 21, 24, 25].

Regardless, the treatment and control of supernumerary parathyroid glands and parathyromatosis remain a challenge, as complete excision of all foci is very difficult. When multiple surgeries fail, medical treatment, including suppression of PTH production with cinacalcet and stabilization of bone mineral density with bisphosphonate, should be considered $[8,14,26]$. In conclusion, parathyromatosis and supernumerary parathyroid glands are very rare causes of persistent hyperparathyroidism in patients undergoing haemodialysis. Multiple imaging modalities are valuable for precise preoperative localization of affected parathyroid tissues and may help with subsequent treatment.

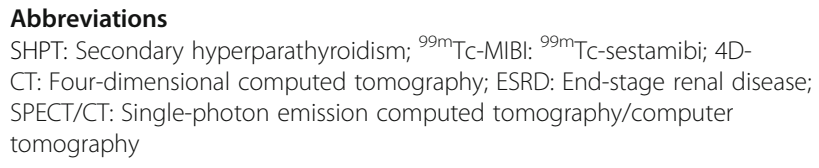

\section{Acknowledgements}

Not applicable.

\section{Authors' contributions}

JY examined and drafted the manuscript. JZ and HL contributed to the interpretation of the clinical data. NL helped draft the manuscript. MD is the corresponding author and organized the study. All authors read and approved the final manuscript.

Funding

Not applicable. 
Availability of data and materials

Not applicable.

\section{Ethics approval and consent to participate}

This study was approved by the Ethics Committee of the First Affiliated Hospital, College of Medicine, Zhejiang University.

\section{Consent for publication}

Written informed consent to publish was obtained from the patient for publication of the case report.

\section{Competing interests}

The authors declare that they have no competing interests.

Received: 26 March 2020 Accepted: 29 June 2020

Published online: 06 July 2020

\section{References}

1. Ketteler M, Block GA, Evenepoel P, Fukagawa M, Herzog CA, McCann L, et al. Diagnosis, evaluation, prevention, and treatment of chronic kidney disease-mineral and bone disorder: synopsis of the kidney disease: improving global outcomes 2017 clinical practice guideline update. Ann Intern Med. 2018;168:422-30.

2. Lau WL, Obi Y, Kalantar-Zadeh K. Parathyroidectomy in the management of secondary hyperparathyroidism. Clin J Am Soc Nephrol. 2018;13:952-61.

3. Aly A, Douglas M. Embryonic parathyroid rests occur commonly and have implications in the management of secondary hyperparathyroidism. ANZ J Surg. 2003;73:284-8.

4. Zhang L, Xing C, Shen C, Zeng M, Yang G, Mao H, et al. Diagnostic accuracy study of intraoperative and perioperative serum intact PTH level for successful parathyroidectomy in 501 secondary hyperparathyroidism patients. Sci Rep. 2016;6:26841.

5. Tai TS, Hsu YH, Chang JM, Chen CC. Recurrent tertiary hyperparathyroidism due to supernumerary parathyroid glands in a patient receiving long-term hemodialysis: a case report. BMC Endocr Disord. 2019:19:16

6. Schneider R, Waldmann J, Ramaswamy A, Fernandez ED, Bartsch DK, Schlosser K. Frequency of ectopic and supernumerary intrathymic parathyroid glands in patients with renal hyperparathyroidism: analysis of 461 patients undergoing initial parathyroidectomy with bilateral cervical thymectomy. World J Surg. 2011;35:1260-5.

7. Matsuoka S, Tominaga Y, Sato T, Uno N, Goto N, Katayama A, et al. Recurrent renal hyperparathyroidism caused by parathyromatosis. World J Surg. 2007;31:299-305.

8. Tublin ME, Yim JH, Carty SE. Recurrent hyperparathyroidism secondary to parathyromatosis: clinical and imaging findings. J Ultrasound Med. 2007;26: $847-51$

9. Reddick RL, Costa JC, Marx SJ. Parathyroid hyperplasia and parathyromatosis. Lancet. 1977;1:549.

10. Lentsch EJ, Withrow KP, Ackermann D, Bumpous JM. Parathyromatosis and recurrent hyperparathyroidism. Arch Otolaryngol Head Neck Surg. 2003;129: 894-6.

11. Stehman-Breen C, Muirhead N, Thorning D, Sherrard D. Secondary hyperparathyroidism complicated by parathyromatosis. Am J Kidney Dis. 1996;28:502-7.

12. Fitko R, Roth $\mathrm{SI}$, Hines JR, Roxe DM, Cahill E. Parathyromatosis in hyperparathyroidism. Hum Pathol. 1990;21:234-7.

13. Meakin JL, Milne CA, Hollomby DJ, Goltzman D. Total parathyroidectomy: parathyroid hormone levels and supernumerary glands in hemodialysis patients. Clin Invest Med. 1989;7:21-5.

14. Hage MP, Salti I, El-Hajj FG. Parathyromatosis: a rare yet problematic etiology of recurrent and persistent hyperparathyroidism. Metabolism. 2012;61:762-75.

15. Mariette C, Pellissier L, Combemale F, Quievreux JL, Carnaille B, Proye C. Reoperation for persistent or recurrent primary hyperparathyroidism. Langenbeck's Arch Surg. 1998;383:174-9.

16. Akerstrom G, Malmaeus J, Bergstrom R. Surgical anatomy of human parathyroid glands. Surgery. 1984;95:14-21.

17. Pattou FN, Pellissier LC, Noël C, Wambergue F, Huglo DG, Proye CA. Supernumerary parathyroid glands: frequency and surgical significance in treatment or renal hyperparathyroidism. World J Surg. 2000;24:1330-4.
18. Daphnis E, Stylianou K, Katsipi I, Stratigis S, Karamitopoulou E, Karkavitsas N, et al. Parathyromatosis and the challenge of treatment. Am J Kidney Dis. 2006:48:502-5

19. Cao H, Zeng M, Fang H, Tang L, Liu W. Parathyromatosis type 2 detected by 99mTc-MIBI SPECT/CT. Gland Surg. 2019;8:806-9.

20. Bunch PM, Kelly HR. Preoperative imaging techniques in primary hyperparathyroidism a review. JAMA Otolanyngol Head Neck Surg. 2018;144:929-37.

21. Haciyanli M, Karaisli S, Gucek HS, Atasever A, Arikan ED, Gur EO, et al. Parathyromatosis: a very rare cause of recurrent primary hyperparathyroidism-case report and review of the literature. Ann R Coll Surg Engl. 2019;101:178-83.

22. Wei WJ, Shen CT, Song HJ, Qiu ZL, Luo QY. Comparison of SPET/CT, SPET and planar imaging using $99 \mathrm{mTc}-\mathrm{MIBI}$ as independent techniques to support minimally invasive parathyroidectomy in primary hyperparathyroidism: a meta-analysis. Hell J Nucl Med. 2015;18:127-35.

23. Pinnamaneni N, Shankar PR, Muthukrishna A. 99mTc MIBI SPECT findings in Parathyromatosis-a rare entity causing recurrent hyperparathyroidism. Clin Nucl Med. 2013;38:443-5.

24. Wei AE, Garrett MR, Gupta A. Parathyromatosis: a rare case of recurrent hyperparathyroidism localized by four-dimensional computed tomography. AACE Clinical Case Rep. 2019;5:384-7.

25. Hamidi M, Sullivan M, Hunter G, Hamberg L, Cho NL, Gawande AA. At el. 4D-CT is superior to ultrasound and Sestamibi for localizing recurrent parathyroid disease. Ann Surg Oncol. 2018;25:1403-9.

26. Aksoy-Altinboga A, Sari AA, Rezanko T, Haciyanli M, Calli AO. Parathyromatosis: critical diagnosis regarding surgery and pathologic evaluation. Korean J Pathol. 2012;46:197-200.

\section{Publisher's Note}

Springer Nature remains neutral with regard to jurisdictional claims in published maps and institutional affiliations.

\section{Ready to submit your research? Choose BMC and benefit from:}

- fast, convenient online submission

- thorough peer review by experienced researchers in your field

- rapid publication on acceptance

- support for research data, including large and complex data types

- gold Open Access which fosters wider collaboration and increased citations

- maximum visibility for your research: over $100 \mathrm{M}$ website views per year

At BMC, research is always in progress.

Learn more biomedcentral.com/submissions 